\title{
Service orientation - a new dimension with educational institutions
}

\author{
R. Kamatchi \\ IT Dept., SIES (Nerul) College of Arts, Science \& Commerce, Plot 1-c, Sector V, Nerul, Navi Mumbai - 400706, India \\ ka_iyer@yahoo.co.in
}

Abstract: The use of distributed systems by enterprises and academics has increased exponentially in recent years. This paper concentrates on the advantages and disadvantages of implementing Service Oriented Architecture in educational institutions and the associated security issues.

Introduction

Today's computer world is mostly operating around the resources. As the number of services and the demand for the same increases, sharing of resources and services has become highly important. The Service Oriented Architecture (SOA) is an initiative for resource sharing and optimum service utilization. The concepts embodied by service-orientation are evolved out of longstanding efforts to modularize and distribute complex computer systems that reflect and support the reality of the distributed business world. As the reusability need for the database increases, the importance of the service distribution also increases.

SOA with educational institutions

Recent years witness many innovative practices in educational systems all around the world. The virtual learning and elearning are the known examples. As the service utilization increases among the organizations, the importance of SOA has tremendously increased. There are several services, which can be kept common with in the educational institutions viz. library, projects, placement services etc. This will avoid unnecessary duplication of the databases at multiple locations. Even though the method of invoking the services varies, the bases for these services are always centered on the student details such as: 1) admission, 2) library access, 3) examination and 4) placements. These services will be accessed by different users at different levels. Each and every user will have different level of information requirement and may have their own applications to invoke the data. However, it is crucial to have a common interface through which the users can interact with each other in an effective manner. This will minimize the redundancy of different applications available with various users. With the help of this, an enterprise can retrieve the relevant information it required, from the common

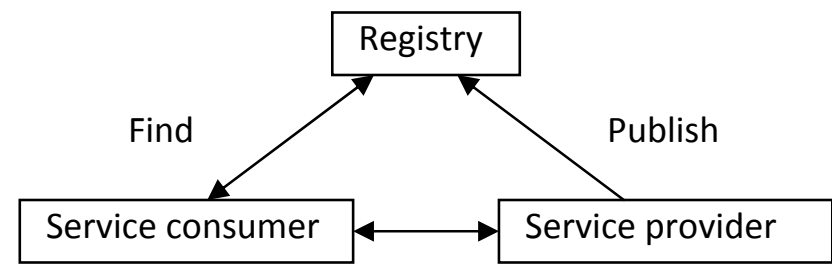

Bind \& Invoke

Sci. Technol. Edu.

CIndian Society for Education and Environment (iSee) educational institutions. database, as per its own specific requirements. Working scenario

As the data is shared among the various users, it has to be stored in a centralized data storage that can be assessed by all. As the same database is shared among various users, appropriate data filters are needed which will channelize only the relevant data as required by every specific user (Shailaja Shirwaikar \& Vidhubala Sridhar, 2008). These data filters are nothing but a set of procedures required to invoke the data as per the specific requirement of each and every users. As soon as the service is invoked, the corresponding application will run and the data filters will ensure that the user will receive only the relevant and appropriate data as needed. For

Fig. 1. The working scenario of SOA with educational institutions

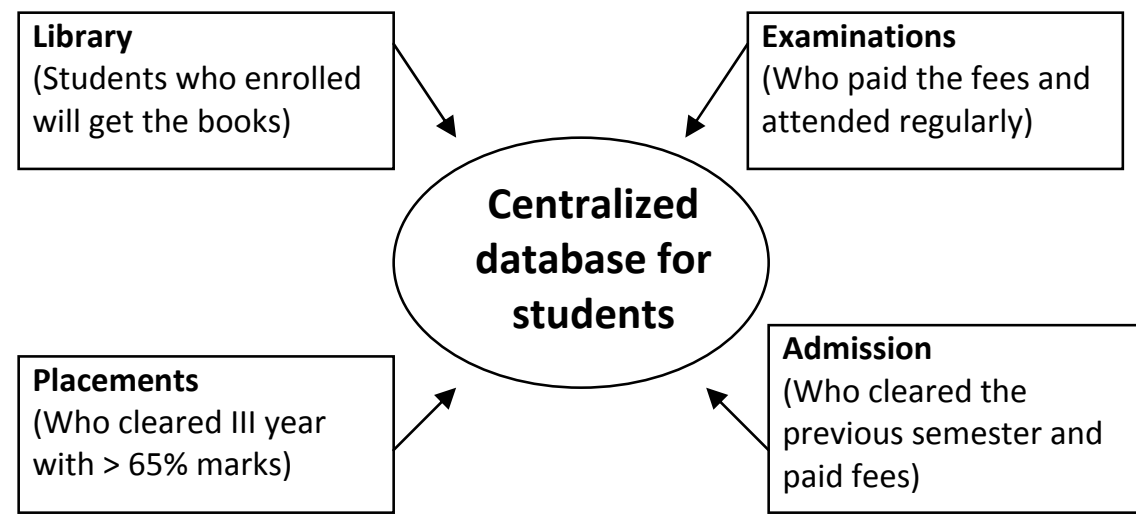

example, the criteria for placement of a student will be the completion of his/her course, whereas the criteria for the library will be his enrollment in the course. Both the procedures will navigate the same database for its data retrieval. Fig. 1 explains the working scenario of SOA with

Fig.1. contains four different services with their own procedure defined. All the four services are accessing the centralized data storage. This system will start functioning with the implementation of web services with the same. Role of SOA

SOA plays three main roles as: 1) Service Provider which creates a Web service and possibly publishes its interface and access information to the service registry, 2) Service Broker, also known as service registry, is responsible for 
making the Web service interface and implementation access information available to any potential service requestor. The implementer of the broker decides about the scope of the broker and 3) Service Requestor or Web service client locates entries in the broker registry using various find operations and then binds to the service provider in order to invoke one of its Web services. Fig. 2 explains the way the services are published with the service registry (James Phelps \& Brain Busby, 2007).

\section{$S O A$ and web services}

As the services are described initially within the modules, then it can be extended and launched beyond boundaries with the help of web services. The data can be centrally stored and the access will be made through SOAP messages (Fig.3). The services and its associated procedures are wrapped together and will be published in the service registry by the service providers. The services can be invoked by the end users (service consumers) by using various web protocols messages, which in turn will locate the service in the registry and invoke the procedure through the provider. In the above-mentioned example, three different services and its procedures to invoke the data are registered into the service registry and the end user (service consumer) can be a student or a teacher or an office administrator (Mohan, 2002).

An Internet web server hosts each web service's Unique Resource Identifier. SOAP messages, which are typically HTTP binding, can be used to define the services.

\section{Institutional benefits}

The educational institutions cannot truly capitalize on an application's process benefits without a wellintegrated, networked software infrastructure. Application middleware enables this integration, pushing applications out to distributed environments and unleashing the domain-specific value of each application.

Case analysis

The sample considered for the analysis is South Indian Educational Society (SIES), which contains various 50 different courses and different branches within Maharashtra. Each and every institution contains several different courses

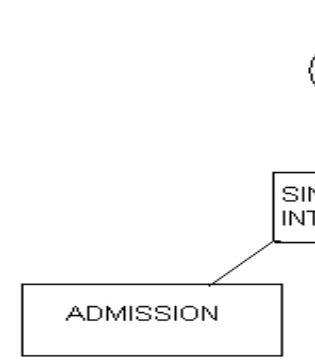

Fig. 4. SOA with the web services

Sci. Technol. Edu.

CIndian Society for Education and Environment (iSee) storage.
Vol.2 No.8 (Aug 2009)

ISSN: 0974- 6846

and in turn each course contains its own database with its own access methods. If we consider a single entity - Arts, Science \& Commerce College, the student database is the common property, which will have a different access pattern within itself with various streams.

Student database is a common database, which is accessed in a different ways with different courses within the same institution (Table 1).

As the number of institutions attached varies, then the complexity of the data handling will also increase considerably. Each and every query will navigate through the entire database and the resultant data will be identified. The better way to bring out a seamless data base architecture among these applications will be the SOA with the web services (Fig.4).

With the help of web services, the data among the various institutions of disparate in nature can be brought

\begin{tabular}{|l|l|}
\hline Course & Admission \\
\hline Science & $\begin{array}{l}\text { Students with minimum 50\% } \\
\text { and Maths as a subject }\end{array}$ \\
\hline Commerce & Students with minimum 45\% \\
\hline Arts & $\begin{array}{l}\text { Students with minimum 40\% } \\
\text { with any subject }\end{array}$ \\
\hline Service---------- Admission
\end{tabular}
into a single place and the required data can be accessed in a way the user requires without affecting each other. All institutions can store the data in a single data warehouse with its own access pattern bundled with the same. The service brokers like middleware can be approached to identify the required service from the registry.

Reusability: The service can be reused several times by different users in different situations. As the services are spread across the systems, it can be utilized many times. In the case of the captioned model, for example, the examination module may be accessed by the student or the office administrator in different situations. The data will be provided to individual user in a way they prefer. Multiple users with different priorities can use the same applications and the data. This kind of sharing may minimize the redundancy of applications and data

Interoperability: In general, each and every user may develop their own unique applications as per ones specific needs. For example, the library module may be developed in Visual Basic with Microsoft. The office module may be developed in JAVA which is supported by Sun Micro System. When the services are shared among the users in an enterprise, the compatibility problem may occur. In other 
words, each and every application will have its own limitation in working in different platform. This problem can be overcome by using the common interface like JNI. Here the web service brokers are getting the importance. The brokers will provide the common interface by which

Fiq.5. Working scenario of interoperable system

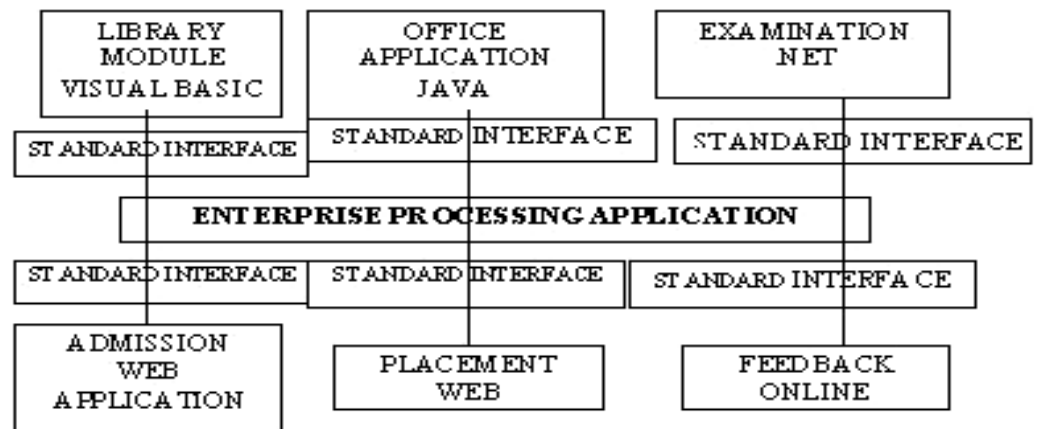

all the systems can find its own comfortable platform to work with and the request and reply will go through. This common interface will take care of the compatibility. Fig. 5 explains the working scenario of the interoperable system, which is going through the standard interface. Each and every application access to the centralized storage is going through the brokers like CORBA, which will take care of the compatibility issues (XML Journal Publication Date: 01-JUL-03).

Cross enterprise integration: Besides providing the cross platform support within the organization, the benefit of the service orientation can also be extended to another organization, which will have similar needs \& working methodology. This can ensure fast and seamless collaboration with different users. As the extent of collaboration with foreign universities are increasing as never before, the service orientation will facilitate the ease accessibility of books and course details between foreign and indigenous universities. This kind of cross platform communication can be enhanced with the help of web services.

Fig.6 represents the concept of cross enterprise integration graphically. The universities are linked with the central e-libraries, which will provide the references and the projects to the students across the institutions wherever it is placed. Once the university education is completed, the student's results details will be linked with the placement agencies and the appropriate placement options will be made available to the students. This seamless flow of information ensures that only the relevant information is available exactly when and where it is needed.

\section{SOA with wireless handheld devices}

With web services, data can be dynamically brought forth from various applications and enterprise databases, and streamed to campus users

Sci. Technol. Edu.

CIndian Society for Education and Environment (iSee)

regardless of the kind of devices they use like laptops, PDA devices or WiFi networks to any locations including beyond the campus walls. This will help the educational institutions efficiently by providing efficient data transfer. With the above-mentioned case the same courses are conducted in various locations with the same institutions. With the extent of handheld devices the data is not required to be carried every time with a storage device. By using the Wireless network access the data can be accessed immediately without any destruction. The mobility of the data will become easy and accurate (XML Journal on Immediate Online Access" dated 01JUL -2003).

\section{Findings}

With the sample considered above, as an initial process the applications can be prepared separately for each process like admission, examination, timetable, teaching plans, online quiz etc. Then the same can be encompassed into a portal developed with PHP and MySql as a backend to provide the cross platform support.

This architecture has been implemented within four different institutions as a sample and demonstrated to different types of users (students, faculties, office staff etc). The benefits were analyzed by taking 30 users in each category under the parameters like simplicity, efficiency, throughput, and accuracy, cost effectiveness etc (Fig.7).

When it was registered with the registry and launched as service (Java Eclipse) using web service connectivity the following benefits could be justified.

1. Reusability - Once developed can be adopted by similar users at different ends.

2. Multiple client support - Different types of consumers like teachers, students, and staff can have the access with similar services.

3. Higher Availability - Because of location transparency, multiple servers may have multiple instances of a service running on them. If a network segment or a machine goes down, a dispatcher can redirect requests to another service without the client's knowledge.

4. Interoperability - The applications and the database is platform independent.

5. Time and Cost - It provides a good Return On

Fig.6. the concept of cross enterprise integration

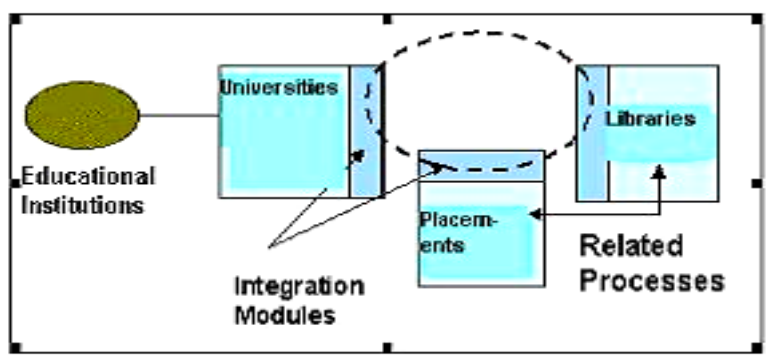

"Service orientation" http://www.indjst.org
Investment (ROI) because of its reusability with various modules. The processing time is also limited because of the accession procedures are also bundled with the same services and the middleware is providing the aids to convert and identify the services from the registry. 


\section{Limitations}

Even though the above-mentioned advantages and the benefits are achieved by the service orientation with educational institutions, various shortcomings are also noted with the same. The middleware issues, security issues are some of the main drawbacks.

\section{Middleware issues}

The middleware are used to provide the interoperability at different levels. This can be purely data-centric, process-based, or policy interoperability. Then the process of interoperability will be simple. But generally the interoperability is a combination of all the three things mentioned above. In the proposed model also requires the same level of interoperability. Because the policy, data, procedure is shared among the services. The service-oriented architecture with the web services is completely depending on the common interface by which the interoperability among the applications achieved. Even though the middleware is supporting various different platforms, the Microsoft products are not completely supported by the common interface like JNI. To overcome this kind of problems the open sources are providing the better solutions. The applications developed with Microsoft platform can be supported by the open source databases like MySql as a backend, which will provide the compatibility among the applications. This problem can be solved in another way by using hand held devices in the accessing process. The data stored in the centralized storage can be accessed by using PDA devices. The integration problem with SOA can be largely solved by using open source applications (Prakasha, 2008).

\section{Compatibility with legacy systems}

Normally the educational institutions will prefer to work with its own standalone applications with own specifications and modifications. The integration and the application distribution will be costly and complex for the normal users to deal with. Indian educational system is highly conventional which is mainly depending upon the policies and the grants from the government. Even though the process of globalization has created an importance for the virtual and e-learning models, the reach of this technology to the rural areas are always debating.

\section{Security issues}

Authenticity: As the services are spread across the systems the authenticity of the users will be a difficult problem. When the individual users are operating then the entry point to the application and the data will be single. In the SOA architecture the applications are shared by multiple users, which in turn will have multiple entry point will introduce the authenticity problem.

Privacy: Even though the data is accessed based on the individual procedures, multiple users access the common base. This kind of accessing method may question privacy of the data. The individual data protection will be a general with this kind of service orientation. Generally the security policies are coming with two common properties such as the purpose of identification and limiting the use, disclosure and retention.

\section{Conclusion}

This service orientation with the educational institutions will be highly beneficial in such a way that it can provide data rich, platform independent, services. Even though certain shortcomings like middleware issues and the security problems are present with the current scenario, this can be improved in the future. This will definitely bring out a new progress in the educational field.

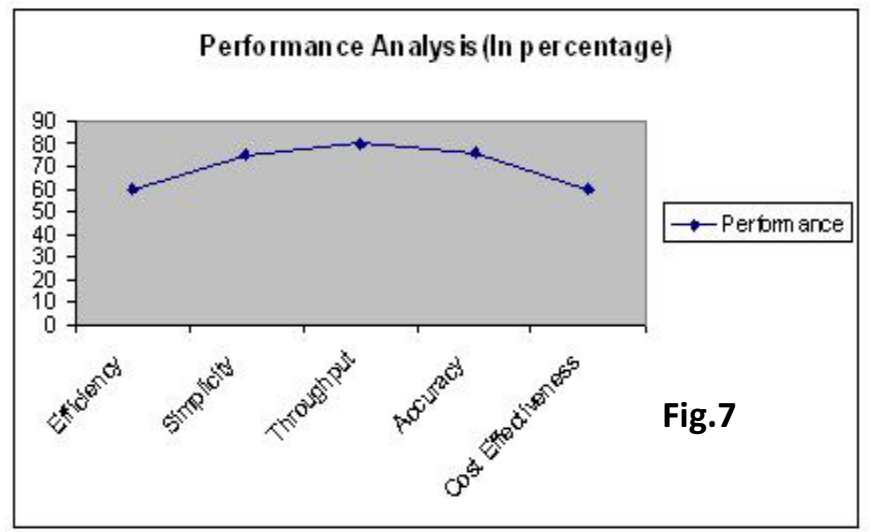

References

1. James Phelps and Brain Busby (2007) Web services Overview EDUCAUSE Librarian. 30, 3.

2. Mohan (2002) Dynamic E-business. Trends in Web Services. Site domain: http://citeseer.ist.psu.edu/ cachedpage/535393/2.

3. Prakasha S (2008) Service Oriented Architecture Overview Computer Society of India. 32 (3) 21.

4. Shailaja Shirwaikar and Vidhubala Sridhar (2008) Service Oriented Architectural Framework for Education Industry Computer Society of India. 32 (1), 38.
Sci. Technol. Edu.

(C)Indian Society for Education and Environment (iSee)
"Service orientation" http://www.indjst.org
Kamatchi

Indian J.Sci.Technol. 